\title{
Leukocyte Adhesion Deficiency in Children and Irish Setter Dogs
}

\author{
THOMAS R. BAUER, JR., YU-CHEN GU, KATE E. CREEVY, LAURA M. TUSCHONG, \\ LISA EMBREE, STEVEN M. HOLLAND, ROBERT A. SOKOLIC, AND DENNIS D. HICKSTEIN \\ Experimental Transplantation and Immunology, Center for Cancer Research, National Cancer Institute \\ [T.R.B., Y.G., K.E.C., L.M.T., L.E., R.A.S., D.D.H.], Laboratory of Host Defenses, National Institute \\ of Allergy and Infectious Diseases [S.M.H.], National Institutes of Health, \\ Bethesda, Maryland, 20892, U.S.A.
}

\begin{abstract}
ABS
Children with the genetic immunodeficiency disease leuko-
cyte adhesion deficiency, or LAD, develop life-threatening bac-
terial infections as a result of the inability of their leukocytes to
adhere to the vessel wall and migrate to the sites of infection.
Recently, the canine counterpart to LAD, known as canine
leukocyte adhesion deficiency, or CLAD, has been described in
Irish setter dogs. This review describes how the clinical pheno-
type of dogs with CLAD closely parallels that of children with
the severe deficiency phenotype of LAD, thus enabling the
\end{abstract}
CLAD dog to provide a disease-specific, large-animal model for testing novel hematopoietic stem cell and gene therapy strategies before their translation to children with LAD. (Pediatr Res 55: 363-367, 2004)

Abbreviations
CLAD, canine leukocyte adhesion deficiency
LAD, leukocyte adhesion deficiency
GVHD, graft-versus-host-disease

LAD represents one of several genetic diseases of childhood that involve leukocyte functional defects. These disorders have in common the propensity to develop life-threatening bacterial infections. The syndrome that came to be known as LAD was first described nearly $25 \mathrm{y}$ ago in patients with delayed separation of the umbilical cord, neutrophilia, neutrophil defects, and systemic bacterial infections (1-3). Leukocyte functional studies confirmed a neutrophil adhesion defect; flow cytometric and protein analysis indicated the absence of the leukocyte integrins on the cell surface; and molecular analysis demonstrated heterogeneous molecular defects in the leukocyte integrin CD18 subunit $(4,5)$.

The canine analog of LAD, known as CLAD, was originally described in the mid-1970s in Irish setter dogs by Renshaw and colleagues (6), and was termed canine granulocytopathy syndrome. Although studies in the late 1980s indicated that this

Received July 31, 2003; accepted October 14, 2003

Correspondence: Dennis D. Hickstein, M.D., Experimental Transplantation and Immunology Branch, National Cancer Institute, National Institutes of Health, 10 Center Dr., MSC1907, Building 10, Room 12C116, Bethesda, MD 20892, U.S.A.; e-mail: hicksted@mail.nih.gov

Supported by intramural funding from the National Institutes of Health, a division of the Department of Health and Human Services, a U.S. government agency.

DOI: 10.1203/01.PDR.0000111287.74989.1B syndrome was due to deficiency in surface expression of the CD11/CD18 complex (7), the precise molecular defect in the CD18 molecule responsible for CLAD was determined only recently (8).

\section{CLINICAL PHENOTYPE OF LAD AND CLAD}

Recurrent bacterial infections are the hallmark of LAD. A severe infection involving the umbilical stump usually represents the initial presentation. Episodes of severe bacterial infection then ensue throughout the perinatal, childhood, and young-adult years. These infections take the form of severe gingivitis and periodontitis, and recurrent, cutaneous, nonhealing wounds (Fig. 1). These infectious episodes in LAD are accompanied by a leukocytosis ranging from 15,000 to 100,000 cells $/ \mu \mathrm{L}$. Despite the marked leukocytosis, the inability of neutrophils to migrate to the site of infection in LAD results in the absence of pus at the inflammatory or infectious sites (4).

A similar clinical scenario is present in CLAD-affected pups. In CLAD pups, the initial clinical signs manifest shortly after birth with the development of omphalitis. This is followed by severe gingivitis, lymphadenopathy, poor wound healing, low body weight, and episodes of infection manifesting as pyrexia 

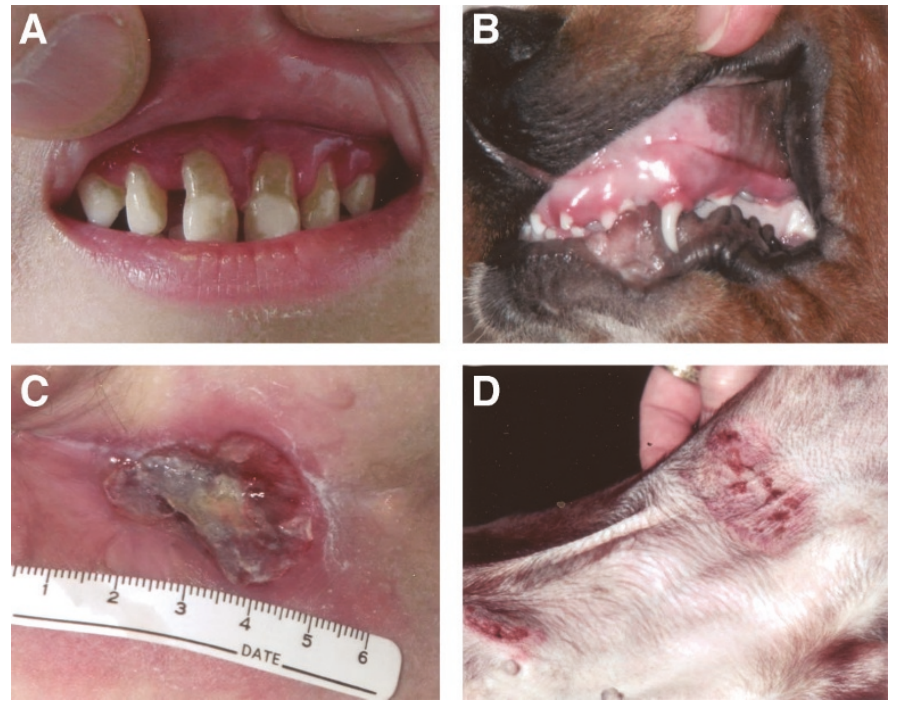

Figure 1. Pathology of LAD in humans and dogs. $(A)$ Severe gingivitis in an LAD patient; $(B)$ extensive gingivitis in a CLAD-affected dog; $(C)$ perianal, nonhealing abscess in a LAD patient; $(D)$ nonhealing skin lesions on a CLAD-affected dog.

and anorexia. A severe leukocytosis of up to 500,000 neutrophils $/ \mu \mathrm{L}$ is a characteristic feature of CLAD. Despite antibiotic therapy, CLAD-affected pups in the community usually die or are euthanized within the first few months of life (9). The functional abnormality in LAD and CLAD responsible for the predominant clinical picture is that of neutrophil adhesion defects. However, lymphocyte function is also affected. Studies in both LAD and CLAD show a decreased in vitro lymphocyte blastogenesis and proliferation $(4,7)$. The clinical relevance of these findings is unclear inasmuch as neither CLAD dogs nor LAD individuals are particularly prone to viral infections.

\section{CHARACTERIZATION OF THE MOLECULAR DEFECT IN LAD AND CLAD}

LAD is inherited in an autosomal recessive manner, and children with LAD are usually compound heterozygotes with a different mutation on each allele of the CD18 gene (also known as the $\beta 2$ subunit of the leukocyte integrin family) (10). Because the CD11 subunits, or alpha subunits, of this adhesion receptor family require the $\mathrm{CD} 18$ subunit for heterodimer formation and surface expression, deficiency of CD18 results in failed, decreased, or aberrant surface expression of the CD11/CD18 complex in LAD (Fig. 2) (11). The majority of LAD cases involve single point or missense mutations in the CD18 subunit, leading to an altered CD18 precursor that is unable to dimerize with the CD11 subunits.

LAD can be categorized as severe or moderate according to quantitative differences in expression of the leukocyte integrins on the cell surface (4). Children with severe deficiency typically display less than $1 \%$ of normal levels of CD11/CD 18 , and children with moderate deficiency typically express $5-10 \%$ of normal levels of CD11/CD18. The severity of clinical complications among children with LAD appears to be directly related to the degree of CD18 deficiency. In one historical study, approximately $75 \%$ of children with the severe deficiency

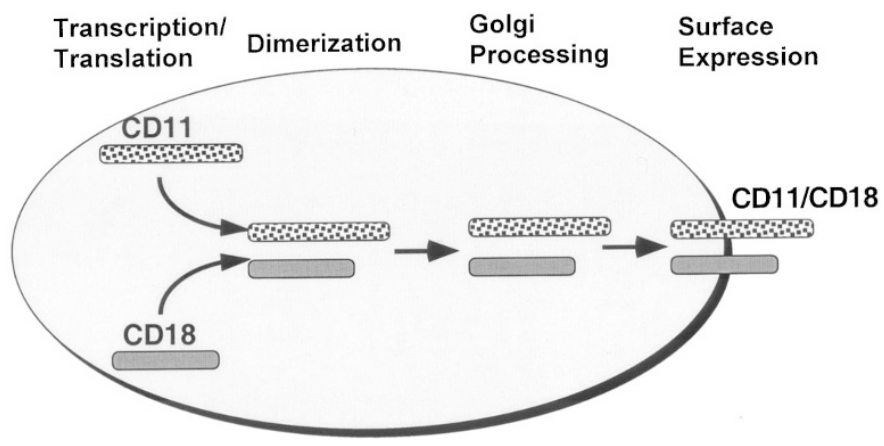

Figure 2. Heterodimer formation and surface expression of the CD11/CD18 adhesion complex. Under normal circumstances, the CD11 and CD18 subunits are synthesized as separate precursors, assembled as a dimer, processed to a higher molecular weight complex in the Golgi, and inserted into the cell membrane. Defects in CD18 in LAD may prevent its transcription or translation, prevent heterodimer formation, or interfere with processing of the CD11/ CD18 complex. Point mutations in the CD18 coding region or at splice sites may lead to decreased expression of the CD18 protein. These mutations all result in severe impairments in the surface expression of the CD11/CD18 complex. With certain rare variant CD18 mutations, a CD11/CD18 heterodimer may become membrane inserted, but not be fully functional.

phenotype of LAD died within the first $2 \mathrm{y}$ of life as a result of extensive bacterial infection (12). Although the prognosis was better for patients in whom the CD18 expression is at least $5-10 \%$ of normal (moderate phenotype), only $25 \%$ will typically survive to age 40 .

In CLAD-affected dogs, the defect in CD18 has been shown to be due to a single point mutation that results in an amino acid substitution (C36S) in a highly conserved cysteine residue in the extracellular domain of CD18 (8). This structural defect in $\mathrm{CD} 18$ results in the failure to express the CD11/CD18 complex on the leukocyte surface. All CLAD-affected dogs identified to date, including Irish red and white setters, carry the identical CD18 mutation (13). Flow cytometric analysis of leukocytes from CLAD-affected puppies demonstrates the complete absence of CD18 expression, analogous to the picture seen in children with the severe deficiency phenotype of LAD (Fig. 3). This finding helps to explain the severity of the clinical phenotype in CLAD.

\section{CONVENTIONAL THERAPY FOR LAD AND CLAD}

Despite the use of prophylactic antibiotic therapy, infections invariably develop in LAD and tend to progress in the face of appropriate antibiotic therapy due to the absence of functional neutrophils. Treatment of infections in LAD depends upon the severity of the clinical condition. Wound infections are a particularly common and vexing problem in LAD patients, and frequently require repeated surgical debridement in addition to a prolonged course of parenteral antibiotic therapy. Infusions of allogeneic granulocytes have been used with limited success in patients with LAD who develop refractory infections.

Antibiotics also represent the first line of therapy in CLAD. However, in the study of Trowald-Wigh et al. (9), all dogs with CLAD succumbed to infection, or were euthanized due to progression of disease, by the age of 6 mo. Recently, we have described a similar clinical picture and outcome in a mixedbreed CLAD colony (14). 
Human LAD-Severe

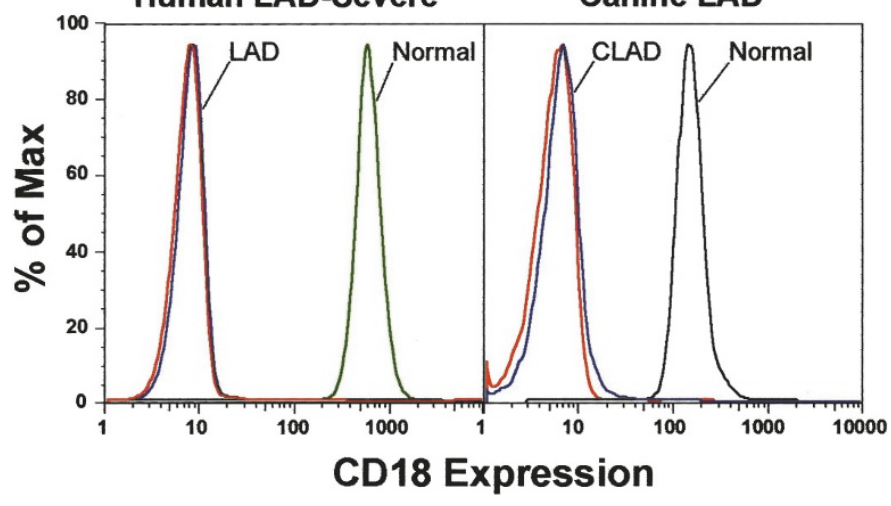

Figure 3. Flow cytometric analysis of neutrophil CD18 expression from a patient with the severe deficiency phenotype of LAD and a CLAD-affected dog. Neutrophils isolated from human or canine peripheral blood were stained with an isotype control antibody (indicated in red) or an anti-human CD18 MAb (which cross-reacts with the canine CD18 molecule). Staining of CD18 on normal human or dog neutrophils is indicated in green and staining for CD18 on neutrophils from an LAD patient and a CLAD dog is shown in blue.

\section{HEMATOPOIETIC STEM CELL TRANSPLANTATION IN LAD AND CLAD}

Allogeneic hematopoietic stem cell transplantation represents the only definitive therapy for LAD. In the largest study involving allogeneic hematopoietic stem cell transplantation for LAD, 14 children with LAD received a myeloablative conditioning regimen followed by bone marrow grafts from either HLA-identical siblings (five patients) or from partially matched family members (nine patients) (15). Of the five children who received HLA-identical grafts, two died of transplant-related complications (infection and GVHD). Although the transplant ultimately resulted in engraftment in 10 patients, 5 required a second transplant due to graft failure, and the overall mortality was $28 \%(15)$. Of note, three of the patients who underwent stem cell transplantation became long-term mixed hematopoietic chimeras, and appeared to be free of disease despite having less than full donor chimerism.

There are subsequent reports in which children with LAD have been cured with allogeneic marrow transplantation using marrow from matched unrelated donors (16), and cord blood from an HLA-identical sibling donor (17). All of these studies used a myeloablative conditioning regimen, and were accompanied by significant regimen-related toxicity and GVHD (18, 19). Complications from GVHD tend to increase in proportion to the degree of mismatch, and because only about $25 \%$ of patients with hematologic diseases will have HLA-identical siblings, a large proportion of patients are at risk of GVHD after hematopoietic stem cell transplantation.

The evidence from the patients with LAD who were mixed donor-host chimeras after myeloablative conditioning before allogeneic transplant suggests several possibilities. First, patients with $\mathrm{LAD}$ appear to require a more intensive conditioning regimen than individuals with other hematologic diseases to achieve full donor chimerism, most likely due to the expanded myeloid bone marrow in LAD patients (12). Second, less than full donor chimerism appears to be sufficient to reverse the disease phenotype in LAD, suggesting that a non- myeloablative conditioning regimen before allogeneic transplant in LAD may be efficacious (15). Nonmyeloablative conditioning regimens result in reduced transplant-related mortality and secondary side effects due to decreased amounts of total body irradiation and chemotherapeutic drugs (20). These reduced conditioning regimens were designed to allow a wider age range of patients to be treated by marrow transplantation, as well as to allow marrow transplantation to be extended to individuals with major organ dysfunction that would preclude the administration of an ablative conditioning regimen.

Nonmyeloablative conditioning regimens have been used successfully to treat other immunodeficiency diseases, including chronic granulomatous disease (21), Wiskott-Aldrich syndrome (22), and Fanconi anemia (23). In those transplants, a minimally toxic regimen of either total body irradiation or cyclophosphamide plus fludarabine resulted in sufficient myelosuppression and immunosuppression to permit engraftment in the majority of patients (21). Of note, a number of these patients became stable, mixed chimeras.

Recently, nonmyeloablative bone marrow transplantation, which resulted in mixed donor-host chimerism, has been performed in CLAD pups (24). These animal studies were approved by the Institutional Animal Care and Use Committee of the National Cancer Institute, National Institutes of Health. Results in two CLAD dogs are shown (Fig. 4). The two dogs with CLAD were transplanted using matched littermate donors after a nonmyeloablative dose of $200 \mathrm{cGy}$ total body irradiation. Both dogs received posttransplant immunosuppression

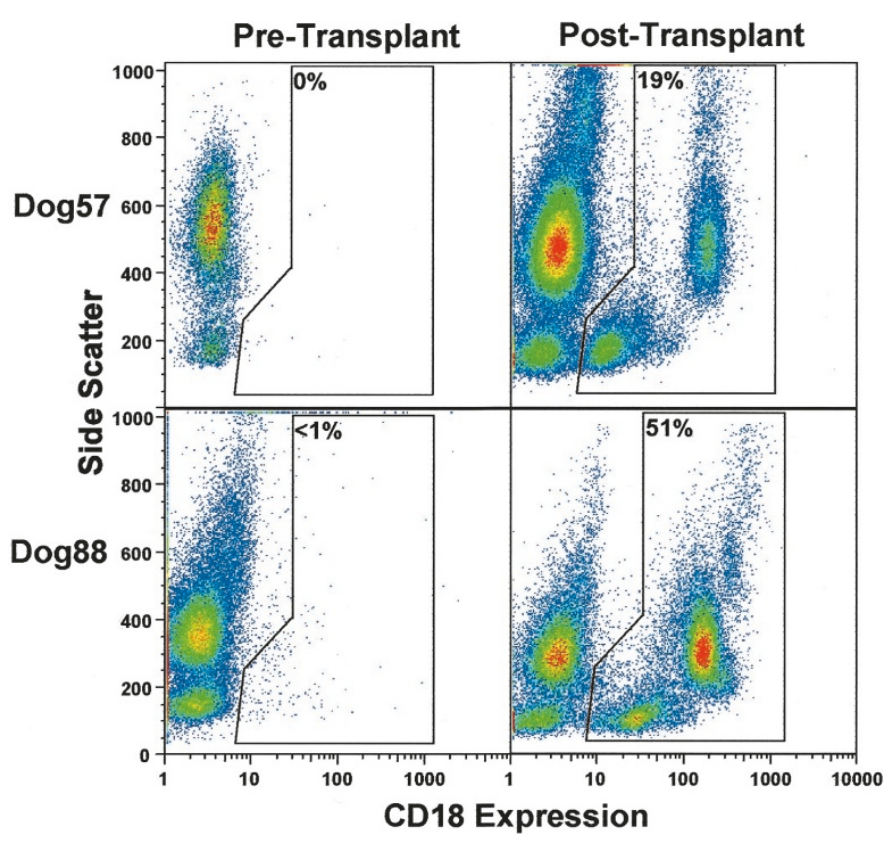

Figure 4. Mixed chimerism after nonmyeloablative conditioning in two CLAD transplanted dogs. Dot plot analysis after flow cytometry of leukocytes from two CLAD dogs before and 1 y (Dog 57) or 9 mo (Dog 88) after hematopoietic stem cell transplantation from a matched littermate donor. The leukocytes that are $\mathrm{CD} 18+$, and hence donor-derived, are indicated by the box. Side scatter is displayed on the $y$ axis, which differentiates the populations including neutrophils and monocytes (high side scatter) from those containing lymphocytes (low side scatter). CD18 expression is displayed on the $x$ axis. 
with cyclosporine for $2 \mathrm{mo}$ and mycophenolic acid for $1 \mathrm{mo}$. Neither dog rejected their graft nor developed GVHD. Moreover, both CLAD dogs have been free of any signs or symptoms of CLAD since the time of engraftment.

Both CLAD dogs became stable, long-term donor-host chimeras, with the percentage of donor leukocytes in the peripheral blood averaging from $19 \%$ in the first dog to $51 \%$ in the second dog (Fig. 4). Mixed chimerism in the transplanted dogs was assessed by flow cytometric analysis of CD18+ cells in the peripheral blood, which can only be donor-derived, and by comparative DNA analysis of PCR amplification of donor and host microsatellite repeat DNA markers.

\section{HEMATOPOIETIC STEM CELL GENE THERAPY IN LAD}

Gene therapy has been attempted as a therapeutic approach in two patients with LAD. In a clinical trial of retroviralmediated gene therapy for LAD, two patients with the severe deficiency form of LAD received a single infusion of autologous, CD18 gene-corrected stem cells (25). Despite the presence of a small $(<0.1 \%)$ population of $\mathrm{CD} 18+$ neutrophils in the peripheral blood of each patient after the infusion of CD18 gene-corrected CD34+ cells, there was no persistence of the CD18 gene marked neutrophils beyond $63 \mathrm{~d}$ after the infusion of transduced cells. These results are consistent with the results in a number of other human gene therapy clinical trials in which the infused hematopoietic stem cells did not possess a selective proliferative advantage.

\section{RELEVANCE OF THE CANINE MODEL OF LAD}

CLAD represents an attractive model for the investigation of novel hematopoietic stem cell transplant regimens as well as hematopoietic stem cell gene therapy approaches for several reasons. First, there is a close relationship between the clinical phenotype of CLAD and the clinical phenotype of LAD. Thus, therapeutic approaches that reverse the disease phenotype in CLAD would be expected to be efficacious in LAD. Second, because reversal of the disease phenotype remains the cornerstone of any therapy in CLAD, and because most CLAD dogs die or are euthanized by 6 mo of age due to infection, this outcome represents a clear end point against which experimental therapies can be compared. Third, the presence and number of donor-derived CD18-positive leukocytes in the peripheral blood is easily detected and quantified by flow cytometry. Therefore, the presence of CD18-positive leukocytes in a treated CLAD dog, after either an allogeneic hematopoietic stem cell transplant or an infusion of autologous, CD18 genecorrected cells, can be correlated with reversal of the disease phenotype.

The canine model itself is well established as an experimental system in which novel hematopoietic approaches to therapy, such as hematopoietic stem cell transplantation and hematopoietic stem cell gene therapy, can be evaluated $(26,27)$. For hematopoietic stem cell transplantation in particular, the dog MHC, known as the dog leukocyte antigen (DLA) locus, has been defined, and has been shown to be similar to the MHC region of humans $(28,29)$; regimens for conditioning before stem cell transplant have been extensively tested in canines; GVHD in the setting of genotypic MHC compatibility was first described in dogs and, as a consequence, therapy to treat GVHD was developed in the dog (30); and insights into issues of hematopoiesis and transplantation derived from canine studies have been successfully translated to humans.

The CLAD model described in this report now provides a disease-specific, large-animal model for assessing new therapeutic approaches that may be translated to LAD.

\section{REFERENCES}

1. Hayward AR, Harvey BAM, Leonard J, Greenwood MC, Wood CBS, Soothill JF 1979 Delayed separation of the umbilical cord, widespread infections, and defective neutrophil mobility. Lancet 1:1099-1101

2. Bowen TJ, Ochs HD, Altman LC, Klebanoff SJ, Page RC, Perkins WD, Carter WB, Wedgwood RJ, Price TH 1980 A cellular chemotactic and adherence defect associated with recurrent bacterial-infections, abnormal umbilical-cord separation, and severe periodontitis. Pediatr Res 14:544A(abstr)

3. Crowley CA, Curnutte JT, Rosin RE, André-Schwartz J, Gallin JI, Klempner M, Snyderman R, Southwick FS, Stossel TP, Babior BM 1980 An inherited abnormality of neutrophil adhesion: its genetic transmission and its association with a missing protein. N Engl J Med 302:1163-1168

4. Anderson DC, Schmalstieg FC, Finegold MJ, Hughes BJ, Rothlein R, Miller LJ, Kohl S, Tosi MF, Jacobs RL, Waldrop TC, Goldman AS, Shearer WT, Springer TA 1985 The severe and moderate phenotypes of heritable Mac-1, LFA-1 deficiency: their quantitative definition and relation to leukocyte dysfunction and clinical features. J Infect Dis 152:668-689

5. Kishimoto TK, Hollander N, Roberts TM, Anderson DC, Springer TA 1987 Heterogenous mutations in the $\beta$ subunit common to the LFA-1, Mac-1, and p150,95 glycoproteins cause leukocyte adhesion deficiency. Cell 50:193-202

6. Renshaw HW, Chatburn C, Bryan GM, Bartsch RC, Davis WC 1975 Canine granulocytopathy syndrome: neutrophil dysfunction in a dog with recurrent infections. J Am Vet Med Assoc 166:443-447

7. Giger U, Boxer LA, Simpson PJ, Lucchesi BR, Todd III RF 1987 Deficiency of leukocyte surface glycoproteins Mo1, LFA-1, and Leu M5 in a dog with recurrent bacterial infections: an animal model. Blood 69:1622-1630

8. Kijas JMH, Bauer Jr TR, Gäfvert S, Marklund S, Trowald-Wigh G, Johannisson A, Hedhammar Å, Binns M, Juneja RK, Hickstein DD, Andersson L 1999 A missense mutation in the $\beta$-2 integrin gene (ITGB2) causes canine leukocyte adhesion deficiency. Genomics 61:101-107

9. Trowald-Wigh G, Ekman S, Hansson K, Hedhammar Å, Hård af Segerstad C 2000 Clinical, radiological and pathological features of 12 Irish setters with canine leucocyte adhesion deficiency. J Small Anim Pract 41:211-217

10. Kishimoto TK, O'Connor K, Lee A, Roberts TM, Springer TA 1987 Cloning of the $\beta$ subunit of the leukocyte adhesion proteins: homology to an extracellular matrix receptor defines a novel supergene family. Cell 48:681-690

11. Hynes RO 1987 Integrins: a family of cell surface receptors. Cell 48:549-554

12. Fischer A, Lisowska-Grospierre B, Anderson DC, Springer TA 1988 Leukocyte adhesion deficiency: molecular basis and functional consequences. Immunodefic Rev $1: 39-54$

13. Debenham SL, Millington A, Kijas J, Andersson L, Binns M 2002 Canine leucocyte adhesion deficiency in Irish red and white setters. J Small Anim Pract 43:74-75

14. Creevy KE, Bauer Jr TR, Tuschong LM, Embree LJ, Colenda L, Cogan K, Starost MF, Haskins ME, Hickstein DD 2003 Canine leukocyte adhesion deficiency colony for investigation of novel hematopoietic therapies. Vet Immunol Immunopathol 94:11-22

15. Thomas C, Le Deist F, Cavazzana-Calvo M, Benkerrou M, Haddad E, Blanche S, Hartmann W, Friedrich W, Fischer A 1995 Results of allogeneic bone marrow transplantation in patients with leukocyte adhesion deficiency. Blood 86:1629-1635

16. Mancias C, Infante AJ, Kamani NR 1999 Matched unrelated donor bone marrow transplantation in leukocyte adhesion deficiency. Bone Marrow Transplant 24:1261-1263

17. Stary J, Bartunková J, Kobylka P, Vávra V, Hrusák O, Calda P, Král V, Svorc K 1996 Successful HLA-identical sibling cord blood transplantation in a 6-year-old boy with leukocyte adhesion deficiency syndrome. Bone Marrow Transplant 18:249-252

18. Le Diest F, Blanche S, Keable H, Gaud C, Pham H, Descamp-Latscha B, Wahn V, Griscelli C, Fischer A 1989 Successful HLA nonidentical bone marrow transplantation in three patients with the leukocyte adhesion deficiency. Blood 74:512-516

19. Fischer A, Landais P, Friedrich W, Gerritsen B, Fasth A, Porta F, Vellodi A, Benkerrou M, Jais JP, Cavazzana-Calvo M, Souillet G, Bordigoni P, Morgan G, Van Dijken P, Vossen J, Locatelli F, di Bartolomeo P 1994 Bone marrow transplantation $(\mathrm{BMT})$ in Europe for primary immunodeficiencies other than severe combined immunodeficiency: a report from the European group for BMT and the European group for immunodeficiency. Blood 83:1149-1154

20. Mielcarek M, Storb R 2003 Non-myeloablative hematopoietic cell transplantation as immunotherapy for hematologic malignancies. Cancer Treat Rev 29:283-290

21. Horwitz ME, Barrett AJ, Brown MR, Carter CS, Childs R, Gallin JI, Holland SM, Linton GF, Miller JA, Leitman SF, Read EJ, Malech HL 2001 Treatment of chronic granulomatous disease with nonmyeloablative conditioning and a T-cell-depleted hematopoietic allograft. N Engl J Med 344:881-888 
22. Longhurst HJ, Taussig D, Haque T, Syndercombe-Court D, Cavenagh J, Edgar JD, Helbert MR 2002 Non-myeloablative bone marrow transplantation in an adult with Wiskott-Aldrich syndrome. Br J Haematol 116:497-499

23. de la Fuente J, Reiss S, McCloy M, Vulliamy T, Roberts IAG, Rahemtulla A, Dokal I 2003 Non-TBI stem cell transplantation protocol for Fanconi anaemia using HLA-compatible sibling and unrelated donors. Bone Marrow Transplant 32:653-656

24. Creevy KE, Bauer Jr TR, Tuschong LM, Embree LJ, Silverstone AM, Bacher JD, Romines C, Garnier J, Thomas 3rd ML, Colenda L, Hickstein DD 2003 Mixed chimeric hematopoietic stem cell transplant reverses the disease phenotype in canine leukocyte adhesion deficiency. Vet Immunol Immunopatho 95:113-121

25. Bauer Jr TR, Hickstein DD 2000 Gene therapy for leukocyte adhesion deficiency. Curr Opin Mol Ther 2:383-388
26. Storb R, Epstein RB, Ragde H, Bryant J, Thomas ED 1967 Marrow engraftment by allogeneic leukocytes in lethally irradiated dogs. Blood 30:805-811

27. Storb R, Yu C, Wagner JL, Deeg HJ, Nash RA, Kiem HP, Leisenring W, Shulman H 1997 Stable mixed hematopoietic chimerism in DLA-identical littermate dogs given sublethal total body irradiation before and pharmacological immunosuppression after marrow transplantation. Blood 89:3048-3054

28. Sarmiento UM, Storb R 1990 Nucleotide sequence of a dog class I cDNA clone Immunogenetics 31:400-404

29. Burnett RC, DeRose SA, Storb R 1994 A simple restriction fragment-length polymorphism assay for MHC class II gene testing of dog families. Transplantation $57: 280-282$

30. Storb R, Deeg HJ, Raff R, Schuening F, Yu C, Sandmaier BM, Graham T 1995 Prevention of graft-versus-host disease. Studies in a canine model. Ann N Y Acad Sci 770:149-164 